\title{
The Mechanical Properties of 3D Printed CuZn28 Brass Specimens with Different Orientations
}

\author{
Z. SZAKÁL ${ }^{1}$, A. KÁRI-HoRVÁTH ${ }^{2}$, T. PATAKI ${ }^{3}$, M. OdROBINA ${ }^{4}$ \\ ${ }^{1}$ Szent István University, Institute for Mechanical Engineering Technology, szakal.zoltan@gek.szie.hu \\ ${ }^{2}$ Szent István University, Institute for Mechanical Engineering Technology, kari-horvath.attila@gek.szie.hu \\ ${ }^{3}$ Szent István University, Institute for Mechanical Engineering Technology, pataki.tamas@gek.szie.hu \\ ${ }^{4}$ Szent István University, Institute for Mechanical Engineering Technology, odmiklos@gmail.com
}

Abstract. In this paper, the properties of CuZn28 brass raw material were presented. The 3D printed metal specimens are made from this material with different orientations. Their mechanical properties (tensile strength, yield strength) and elongation were investigated according to MSZ EN 6892-1: 2012 standard. The strength of the different printing directions is analyzed and it is determined which printing direction is the most favourable. Finally, the effect of the different printing directions upon the structure of the material is studied.

\section{Introduction}

At the present day, 3D printing is already widespread in the industry, and we can produce not only metal models but also metal parts. Three-dimensional object can be manufactured using laser melting from metal powders. With 3D metal printing technology, external and internal free surfaces or socalled "impossible design" shapes can be created but they cannot be produced using traditional manufacturing technologies. The new 3D metal printing technology is better than the traditional 3D printing, as the parts, which are manufactured by this technology, are not only models, but also ready for use. Component are produced by new technology that can be directly incorporated into machines after machining.

The orientation of 3D printing greatly influences the mechanical properties of parts created by laser sintering technology. According to the technical literature [4], the mechanical properties of 3D printed part vary in different directions, so, the cause of anisotropy can be attributed to the solidification process [6]. The difference depends on the direction of the particle growth. The particles typically start to grow from the colder side to the warmer side. During laser sintering, the colder side is the bottom of the melt, the material there is already melted and solidified. The heat conduction of cooled solid material is much higher than the heat conduction of powder [8]. The top of the melt pool is heated by the laser beam, and the gas atmosphere adjacent to the surface has a much weaker heat transfer ability than a solid metal. Material represents orthotropic behaviour due to the different temperature zones in the build area $[3,7]$. The mechanical properties of 3D printed metal materials depend on the building direction [1], they are not identical within the printed solid. This property is further 
influenced by printing in different directions in the machine's workspace. Rehme et al. [2] investigated the directional dependence of 3D printed metal specimens. 145 repetitions were performed.

The specimens, which made from X2CrNiMo17-12-2 (1.4404) stainless steel for every $15^{\circ}$ angle in shape of hemisphere. The strength of the raw material was measured. The average yield strength of 3D printed specimens were $525 \mathrm{MPa}$ and $486 \mathrm{MPa}$ in the $\mathrm{x}-\mathrm{y}$ and z plane, respectively. A similar deviation was observed for the tensile strength, the tensile strength of the 3D printed specimens in the $x-y$ plane was $605 \mathrm{MPa}$, while the tensile strength of the printed specimens in the z plane was $543 \mathrm{MPa}$. The maximum value, $618 \mathrm{MPa}$, was measured in case of those specimens, which make an angle of $15^{\circ}$ with $\mathrm{x}-\mathrm{y}$ plane. The minimum value, $540 \mathrm{MPa}$, was measured in case of those specimens, which make an angle of $75^{\circ}$ with $x-y$ plane. The maximum and minimum of elongation at breaks are $29,7 \%$ and $10,5 \%$ in case of specimens with $15^{\circ}$ and $75^{\circ}$, respectively. Smaller differences are caused in the mechanical properties by the rotation in the $\mathrm{x}-\mathrm{y}$ plane. The specimens created into $\mathrm{x}$ direction are weaker than the specimens created into y direction. However, the reason for this is due to the optical system, the beam energy in the $\mathrm{x}$ direction was 1.5 times higher than the y direction because of the inaccuracy of collimator lens, so components, which created with higher energy density in the y direction had higher strength. Dependence on the direction can therefore be influenced by beam quality and optical system. However, the building direction does not affect the modulus of elasticity, since the modulus of elasticity does not depend on the crystal structure, but depends on the microstructure [2]. The scanning strategy means the lighting method of the layers. It has a great influence on the thermal conductivity, the structure of material and the growth direction of the particles during the solidification. The choice of strategy therefore influences not only the production time, but also the quality of the product both in terms of mechanical and roughness. One of the features of the component created by the additive manufacturing technology is the anisotropy.

\section{Method}

The change of mechanical properties of the copper alloy powder (CuZn20) available on the market have been investigated due to the modification of manufacturing parameters. The machine settings have been varied to achieve the highest strength. It was a question of whether the manufacturer's strength values could be produced with the best technological parameters.

Factors influencing the strength of the finished product:

- The moisture content of the raw material.

- Lighting and sintering strategy.

- Laser energy.

- Backfill.

- Printing orientation.

The building directions affect not only the print time, but also the mechanical properties of the workpiece as well as the amount of support material and the surface quality of the workpiece. According to our experience, it is worth inserting the workpiece into the workspace of 3D printer that its flat surfaces form $45^{\circ}$ angle to the machine table. In this orientation, the flat surfaces will be best. 
The notable 3D printing directions of the machine are studied. Various parameters were measured by tensile testing machine according to MSZ EN 6892-1:2012 standard. Measurements were repeated five times in all cases. For the measurements, a Zwick Roel Z100 universal tensile test machine was used.

The specimens were produced by Thinkspace CL/CTS2 Pro 3D printer. The build size of the machine: 250 x 250 x $280 \mathrm{~mm}(\mathrm{x}, \mathrm{y}, \mathrm{z})$. The different printing arrangements are illustrated in Figure 1.

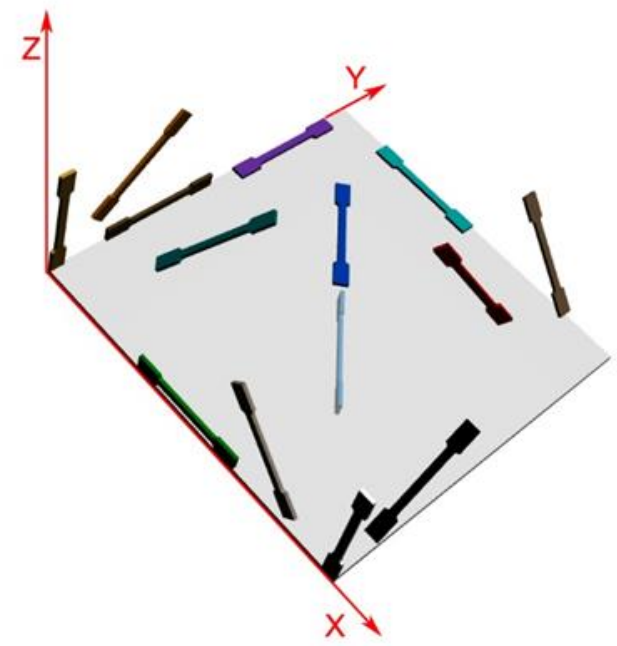

Figure 1. Specimens in the build area of $3 D$ printer

The specimens are labelled as follows: the first two characters represent the plane of the print and the third character indicates the building direction. For example, the xy_x marking means that the specimen was created in the plane of the machine and the powder was spread parallel to the $\mathrm{x}$ axis.

\section{Material}

CuZn28 is a solid solution strengthened copper alloy containing 28\% zinc (brass). The alloy has very good cold forming properties and can be brazed and soldered, welding processes need to be executed with care, due to the high zinc content. As the zinc content increases, the strength improves, yet the conductivity and ductility are reduced and the alloy gets more susceptible to stress corrosion cracking if exposed to an ammonia atmosphere, compared to pure copper. If exposed to an ammonia atmosphere, CuZn28 should be stress relieved. Due to the raised zinc content the alloy has economic advantages. Fields of application are metal ware and deep drawing parts, automotive, heat exchangers, connectors, chains, coolers and components of electrical and mechanical engineering.

\begin{tabular}{c|c|c|c|c|c|c}
\hline $\mathrm{Cu}$ & $\mathrm{Fe}$ & $\mathrm{Pb}$ & $\mathrm{Zn}$ & $\mathrm{Al}$ & $\mathrm{Ni}$ & $\mathrm{Sn}$ \\
{$[\%]$} & {$[\%]$} & {$[\%]$} & {$[\%]$} & {$[\%]$} & {$[\%]$} & {$[\%]$} \\
\hline $71-73$ & $0.05 \max$ & $0.05 \max$ & rem & $0.02 \max$ & $0.3 \max$ & $0.1 \mathrm{max}$ \\
\hline
\end{tabular}

Table 1. The chemical composition of the measured copper alloy. 
This alloy is in accordance with RoHS 2002/96/CE for electric \& electronic components and 2002/53/CE for the automotive industry. Mechanical properties of these materials are shown in Table 2.

\begin{tabular}{c|c|c|c|c|c|c}
\hline & $\begin{array}{c}\text { Tensile } \\
\text { Strength } \\
{[\mathrm{MPa}]}\end{array}$ & $\begin{array}{c}\text { Yield } \\
\text { Strength } \\
{[\mathrm{MPa}]}\end{array}$ & $\begin{array}{c}\text { Elongation } \\
A_{50} \\
{[\%]}\end{array}$ & $\begin{array}{c}\text { Hardness } \\
\mathrm{HV}\end{array}$ & \multicolumn{2}{c}{$\begin{array}{c}\text { Bend ratio } \\
90^{\circ}[\mathrm{r}]\end{array}$} \\
& {$[-]$} & $\mathrm{GW}$ & $\mathrm{BW}$ \\
\hline $\mathrm{R} 270$ & $270-350$ & $\leq 160$ & $\geq 40$ & $55-90$ & 0 & 0 \\
\hline R350 & $350-430$ & $\geq 170$ & $\geq 21$ & $95-125$ & 0 & 0 \\
\hline R410 & $410-490$ & $\geq 260$ & $\geq 9$ & $120-155$ & 0 & 0 \\
\hline R480 & $480-560$ & $\geq 430$ & $\geq 4$ & $150-180$ & 0 & 1 \\
\hline R550 & $550-640$ & $\geq 530$ & $\geq 2$ & $170-200$ & 0.5 & 2 \\
\hline R630 & $\geq 630$ & $\geq 610$ & - & $\geq 190$ & 1 & 3 \\
\hline
\end{tabular}

Table 2. The mechanical properties

\section{Results}

CuZn28 specimens in different orientations are made by 3D printing. 5 pieces of each orientation specimen are printed. The results of the measured strength parameters can be seen in Table 3 . The yield strength $(\mathrm{Rp} 0,2)$, the ultimate tensile strength $(\mathrm{Rm})$ and the modulus of elasticity (E) have been determined. 70 pieces of specimens made from CuZn28 were broken. The stress-strain diagram of a specimen can be seen in Figure 2. According to the diagram, the material is capable of a significant deformation, in this case 23\%. Furthermore, the decrease of force is not visible during the loading, despite the large deformation, the material has behaved brittle.

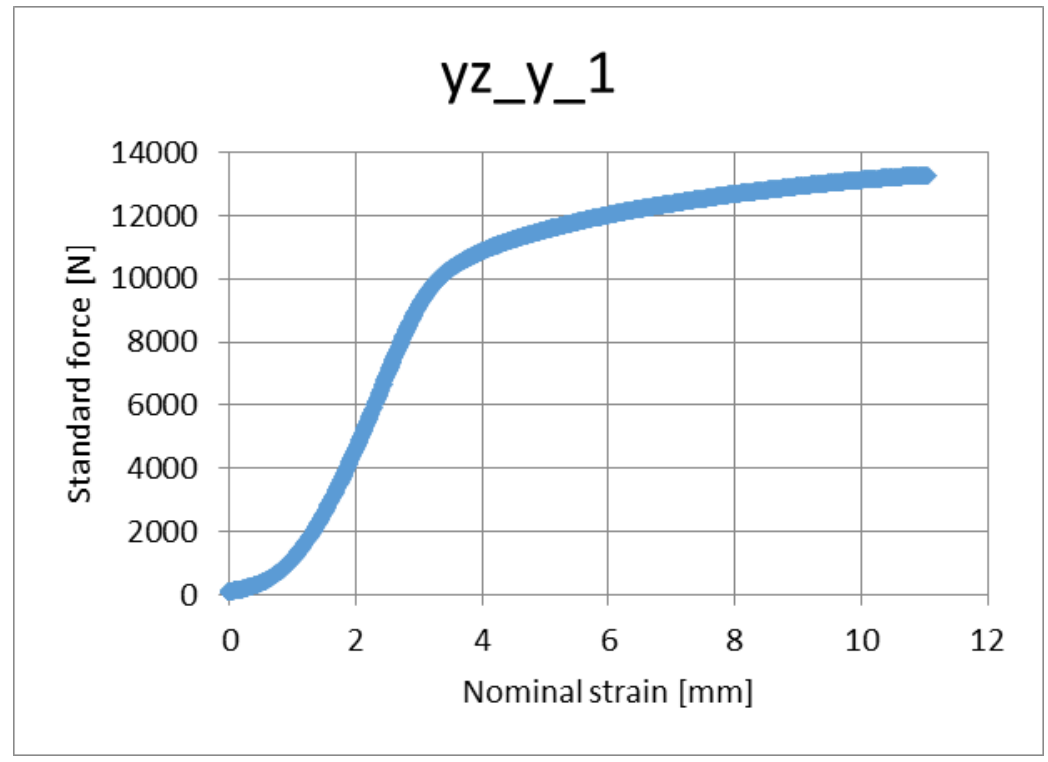

Figure 2. The stress-strain diagram

The tensile tests were carried out at room temperature. Measurements were made by MSZ EN 68921:2012 standard. In each measurement direction, 5 pieces of specimen were tested. 


\begin{tabular}{|c|c|c|c|c|}
\hline & Direction & $\begin{array}{c}\mathbf{R}_{\mathbf{p} 0,2} \\
{[\mathrm{Mpa}]}\end{array}$ & $\begin{array}{c}\mathbf{R}_{\mathbf{m}} \\
{[\mathrm{Mpa}]}\end{array}$ & $\begin{array}{c}\mathbf{E} \\
{[\mathbf{G P a}]}\end{array}$ \\
\hline 1 & $\mathbf{x y \_ x}$ & 433 & 577 & 12,3 \\
\hline 2 & $x y \_y$ & 423 & 573 & 11,9 \\
\hline 3 & xy_45 & 408 & 498 & 25,5 \\
\hline 4 & $\mathbf{X z} \_\mathbf{x}$ & 412 & 502 & 12,6 \\
\hline 5 & $\mathbf{X Z} \_\mathbf{Z}$ & 431 & 505 & 12,8 \\
\hline 6 & $x z_{-} 45$ & 423 & 474 & 28,9 \\
\hline 7 & yz_y & 411 & 524 & 12,2 \\
\hline 8 & $y z \_z$ & 403 & 567 & 12,5 \\
\hline 9 & $y z \_45$ & 414 & 516 & 26,7 \\
\hline 10 & $x y z \_45$ & 421 & 553 & 45,1 \\
\hline
\end{tabular}

Table 3. Results

Based on the results, the values of the strength parameters do not depend on the direction of printing. The average yield strength is (Rp0.2) $417 \mathrm{MPa}$. The average tensile strength is (Rm) $529 \mathrm{MPa}$. The modulus of elasticity is largely dependent on the orientation of the printing in this case. The modulus of elasticity can be up to 3.5 times the same strength parameter, but the highest value is only $45 \mathrm{GPa}$.

\section{Summary}

This study focuses on the strength properties of the CuZn28 material in terms of the printing orientation. Specimens were made in various notable directions of the machine workspace by 3D printing. According to the technical literature, the 3D printed specimens, which made in different orientations, are anisotropic. Compared to the literature data, it is concluded that the strength parameters do not depend on the printing orientation in case of brass. The strength parameters of 3D printed brass correspond to the brass produced by conventional technology. Based on our measured data, it is considered that the highest modulus of elasticity of 3D printed brass is half of the material produced by traditional technology.

\section{References}

[1] M. F. Ashby - L. J. Gibson (1997) Cellular solids: structure and properties. In Cambridge University Press. Cambridge New York.

[2] D. A. Ramirez - L. E. Murr - E. Martinez - D. H. Hernandez - J. L. Martinez - B. I. Machado - R. B. Wicker (2011) Novel precipitate-microstructural architecture developed in the fabrication of solid copper components by additive manufacturing using electron beam melting. Acta Materialia, 59 (10) pp. 4088-4099.

[3] L. E. Murr - S. M. Gaytan - F. Medina - H. Lopez - E. Martinez - B. I. Machado, B. I. - J. Bracke (2010) Next-generation biomedical implants using additive manufacturing of complex, cellular and functional mesh arrays. Philosophical Transactions of the Royal Society of London A: Mathematical, Physical and Engineering Science. 368(1917) pp. 1999-2032.

[4] P. Hanzl - M. Zetek - T. Bakša - T. Kroupa (2015) The influence of processing parameters on the mechanical properties of SLM Parts. Procedia Engineering. 100 pp. 1405-1413. 
International Journal of Engineering and Management Sciences (IJEMS) Vol. 4. (2019). No. 1

DOI: 10.21791/IJEMS.2019.1.32.

[5] Material Datasheet CuZn28, Aurubis

[6] T. S. Keller - Z. Mao, Z. - D. M. Spengler (1990) Young's modulus, bending strength, and tissue physical properties of human compact bone. Journal of Orthopaedic Research. 8(4) pp. 592-603.

[7] B. Vandenbroucke - J. P. Kruth (2007) Selective laser melting of biocompatible metals for rapid manufacturing of medical parts. Rapid Prototyping Journal. 13(4) pp. 196-203.

[8] Z. Jian - L. Deying et al. (2012) Simulation of Temperature Field in Selective Laser Sintering of Copper Powder. 